\title{
MANAGEMENT IN HEALTH CARE
}

A Theoretical and Experiential Approach

\author{
Elaine Lynne La Monica EdD FAAN \\ Professor of Nursing Education \\ Teachers College, Columbia University, New York \\ and \\ Consultant in Management for Health Care
}

Additional material for the Macmillan adaptation by

Philip lan Morgan, BA Hons MA PhD

Lecturer in Human Resource Management

Cardiff Business School,

University of Wales College of Cardiff 


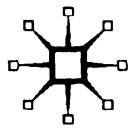

(C) Springer Publishing Company, Inc. 1990

Adaptations for Macmillan edition (c) Philip I. Morgan 1994

All rights reserved. No reproduction, copy or transmission of this publication may be made without written permission.

No paragraph of this publication may be reproduced, copied or transmitted save with written permission or in accordance with the provisions of the Copyright, Designs and Patents Act 1988, or under the terms of any licence permitting limited copying issued by the Copyright Licensing Agency, 90 Tottenham Court Road, London W1T 4LP.

Any person who does any unauthorised act in relation to this publication may be liable to criminal prosecution and civil claims for damages.

The authors have asserted their rights to be identified as the authors of this work in accordance with the Copyright, Designs and Patents Act 1988.

First published 1990 by

Springer Publishing Company, Inc.

536 Broadway

New York, NY 10012

under the title

Management in Nursing:

An Experimental Approach That Makes Theory Work For You

Written by Elaine Lynne La Monica

Published by

PALGRAVE MACMILLAN

Houndmills, Basingstoke, Hampshire RG21 6XS and

175 Fifth Avenue, New York, N. Y. 10010

Companies and representatives throughout the world

PALGRAVE MACMILLAN is the global academic imprint of the Palgrave Macmillan division of St. Martin's Press, LLC and of Palgrave Macmillan Ltd. Macmillan ${ }^{\oplus}$ is a registered trademark in the United States, United Kingdom and other countries. Palgrave is a registered trademark in the European Union and other countries.

ISBN 978-0-333-56386-1

ISBN 978-1-349-23156-0 (eBook)

DOI 10.1007/978-1-349-23156-0

This book is printed on paper suitable for recycling and made from fully managed and sustained forest sources.

A catalogue record for this book is available from the British Library.

$\begin{array}{lllllll}11 & 10 & 9 & 8 & 7 & 6 & 5\end{array}$

$\begin{array}{llllll}08 & 07 & 06 & 05 & 04 & 03\end{array}$ 
Dedicated to

My best friend,

Robert S. Rigolosi

For feeling without saying

And

For saying with feeling. . .

Always. ...

Elaine Lynne La Monica 
Elaine L. La Monica, EdD, FAAN, is Professor of Nursing Education at Teachers College, Columbia University, New York. Currently, she is also Director of the Institute of Research and Service in Nursing Education. Her formal education includes a Doctor of Education degree in human relations and counseling from the School of Education, University of Massachusetts, Amherst; a Masters of Nursing in medical and surgical nursing administration from the College of Nursing, University of Florida, Gainesville; and a Bachelor of Science in nursing from Columbia Union College, Takoma Park, Maryland.

In addition to administrative and academic responsibilities at Teachers College, Dr La Monica maintains a private consulting practice in management for health care organizations and other public and private industries throughout the US, Canada and overseas. She also conducts training programmes on organizational behaviour both nationally and internationally.

Scholarly activities included serving as the Management Briefs Editor for The Journal of Nursing Administration and as a frequent author on management, empathy, and related topics in professional journals. Dr La Monica's most recent books are Nursing Leadership and Management: An Experiential Approach, 1986, and The Humanistic Nursing Process, 1985; both are published by Jones and Bartlett, Boston, Massachusetts. The La Monica Empathy Profile, 1986, published by XICOM, Inc., Sterling Forest, Tuxedo, New York, is an instrument for measuring empathy in helpers-teachers, nurses, managers, and other care givers.

Dr La Monica maintains membership in the following professional organizations: American Academy of Nursing, American Nurses Association, American Psychological Association, New York State Nurses Association, and Sigma Theta Tau-Alpha Theta Chapter, an honour society for nurses.

This book is an adaptation of Management in Nursing: An Experiential Approach That Makes Theory Work For You, solely authored by Dr Elaine La Monica, and published by Springer Publishing Company, New York, 1990. 
Philip I. Morgan, PhD, MA, BA(Hons), is a lecturer in Human Resource Management at Cardiff Business School, University of Wales. His formal education included a BA with Honours in Business Administration from Strathclyde University and doctoral studies at The Ohio State University.

Dr Morgan has taught management subjects at universities in the US and the UK at postgraduate and undergraduate levels. In addition to teaching and academic responsibilities, he researches, lectures, and consults for various public and private organizations, including various hospitals in the UK. His research interests include Organisational Development and Total Quality Management issues related to the National Health Service.

Dr Morgan's additions to Dr Elaine L. La Monica's book are identified by footnotes, as are the chapters of which he is the sole author. 


\section{Acknowledgments}

Even though the author first imagined and then created this book, the theory, exercises, and philosophy represented have been derived from many personal and professional resources. Some materials are original, and some are from established sources to whom credit is most gratefully given; others have evolved from an interchange with professionals and learners whose commitment has been to quality. I would like particularly to thank Donald Carew, Kenneth Blanchard, and Paul Hersey, whose teachings and writings were the foundation of my doctoral education and are the cornerstones of my current professional activities; Frederic Finch for sharing his knowledge; Phil Graf for his reinforcement and assistance-for believing many years ago that I had something to offer future managers; and my colleagues in education and practice for the constant interchange that has shaped today.

To all who have moulded my beliefs, to all from whom I have received, I express my sincere gratitude.

Elaine Lynne La Monica 


\section{Preface}

It is widely recognized that health care professionals must become effective managers and leaders in order to fulfil their responsibilities to themselves, to their clients, and to the professions. Practice environments, roles, and educational programmes are expanding. There is an actual and projected decline in the numbers entering the professions; there is an actual and projected need for increased professional services due to changing demographics of the population and crises emanating from disease states.

Other trends in health care include (a) changing emphases imposed by federal and state cost-containment regulations; (b) changing and alternative methods for health care delivery; (c) increasing focus on health maintenance-primary care-in addition to the ever-present foci on secondary care and tertiary care; and (d) greater quantities of data to support the mind/body relationship in health and disease, suggesting that not only is cure important, but altering behaviours is crucial so that the need to cure may be unnecessary or less frequent.

Wherever their placement in the health care arena, health care managers will be leaders of themselves; of colleagues and peers in interdisciplinary clinical teams, of technicians and other health care providers; of colleagues in various management levels within formal health care organizations; of the public sector through media; of the individual clients, in city, state, national, and international political entities, and so forth. In these placements, they will be called upon for creative strategies, disciplined and cost-contained programmes, and the abilities to research and analyse systems critically and chart growth-all in response to rapid health care changes. It is therefore mandatory that professionals perceive themselves in the roles of managers and leaders and increase their knowledge and application of theory and research in practice so that quality, comprehensive, efficient care is provided to clients in any setting.

Leadership and management involve processes that are essential in making any health care role, in any environment, alive. Disciplines and professions such as organizational behaviour, educational administration, and business have developed theories that assist managers in increasing the probability of achieving specified goals. Managers must apply these 
theories into leadership and management, and then extend them into theory through research. Responsibility and authority granted by a practice act, an institution, an individual's unique experience and personality, and one's personal philosophy on the constituents of quality care and effective management, must be integrated with knowledge and an ability to apply existing theories of management in health care practice.

This book covers the processes of management and leadership in health care practices. It evolves from my experience in teaching future managers of health care personnel in the delivery of care. Content focuses on increasing organizational effectiveness in service and practice. Theories and concepts from the professions of business, organizational psychology, and educational administration are applied to topics in each chapter.

Sections of the book include simulations (for example, case presentations and multimedia activities) to provide practice experiences that illustrate the content of the chapters, as well as to expand the learner's range of experience. The simulations comprise the experiential approach; they provide learners with an opportunity to observe, experience, and carry out new behaviours in a safe, low-risk practice environment. Careful explanations are provided for each simulation. The textbook and exercises are designed for use both in self-learning and classroom environments, in both individual and group learning experiences. It is suggested that study be weighted so that more time is devoted to the experiential elements, since enriched learning in management is derived more from actual and vicarious experiences than from reading and studying the printed word.

This book is written primarily for undergraduate students in health care management and leadership courses. It is also intended as a resource for graduate administration students, practitioners, learners in inservice and continuing education programmes, and faculty.

It is a pleasure to have Dr Morgan's additions in the Macmillan version of this book and to have had the opportunity to work with Dr Morgan on the adaptation. 


\section{Introduction}

Management and leadership in health care involve an individual's efforts to influence the behaviour of others in providing direct, individualized, professional care. The basic premise of management is that managers set goals that represent some level of growth for a particular group in a particular environment. Managers then develop strategies for reaching these goals. Results are evaluated and altered or new directions are set. There is no value of good or bad to the actual state of the group, the group's goals, or the outcomes. Managers simply and constantly design strategies for moving groups of personnel to more efficient and more qualitative levels of functioning. The actual beginning points and the end points are of lesser importance than is the process of constantly developing strategies that result in identifiable, effective, and positive growth. In conducting these processes, managers plan, organize, motivate, and control the work of other allied health care personnel in the delivery of professional care.

The processes of management and leadership are based on a scientific approach called the problem-solving method. The function of this scientific method is to increase the probability of success for a manager's actions, given the particulars of a unique environment. In a typical health care environment, there are staff members, clients, managers, situational variables such as policies and norms, and material resources; these are unique since it would be impossible to find this exact environment in another place or time. The goal of the manager is to identify the environment's resources and to put them to work as a whole system in accomplishing goals and facilitating growth. Use of the scientific method in management simply assists the manager in assessing many needs of the system and in choosing the priorities, identifying the people and situational elements that are important in carrying out specified goals, critically assessing the strengths of those people, and developing strategies that put those strengths to work.

A manager can be functional in the role without using the problemsolving method. This alternative, called "seat-of-the-pants" management, evolves from following only impulses and personal beliefs about self and others. Such management comes from involuntary behaviours that do not 
involve thinking about what a group needs from the manager in order to accomplish its goals. It is possible for seat-of-the-pants management to be successful. That is, by some stroke of luck, the impulses, beliefs, and behaviours of this manager are exactly what the system requires. Though possible, however, such success is unlikely.

Use of a scientific approach brings no guarantee of success; there is no way to predict the behaviour of others with complete accuracy. An effective manager analyses an environment and chooses the best strategy for achieving a specified goal, given the particular strengths and weaknesses of the employees who will be working to carry out that goal. There is always some unknown that cannot be controlled-the risk factor. Because all managers desire success, their goal in choosing the best strategy should be to identify the strategy that balances the lowest risk factor with the highest rate of return. This automatically increases the probability for success. A manager who uses seat-of-the-pants thinking will have a higher risk factor in every undertaking than will the manager who applies a scientific approach. The scientific management method forces the manager to plan, organize, motivate, and control logically and analytically. Further, it allows the manager to build contingency plans for all possible outcomes rather than to face problems unprepared.

Why does use of the scientific method offer so much? It is derived from methodologically sound research within the disciplines and professions of business, educational administration, and psychology-the purists in management. Given the numerous investigations that allow the label theory to be attached to a process or belief, the results suggest that this theory, applied in a particular way, produces these outcomes at least $95 \%$ of the time. A person who simply or randomly guesses in all decisions has an equal chance of being right or wrong. Managers, however, should not be satisfied with such a ratio-this is mediocrity. The use of intuition is appropriate and necessary only after the application of theory. It is the à la mode on home-made apple pie.

Parts I and II, "Conceptual Framework" and "Manager Responsibilities", present the process steps of health care management and leadership. Each chapter has its own conceptual and theoretical discussions with health care applications. In Chapter 7, the whole process of health care management and leadership is presented through a case study. Part III, "Management Skills", takes a close look at the specific skills that managers must use to implement the management process effectively in a variety of health care environments. Part IV studies management processes that increase understanding of health care structure.

An experiential approach in learning management and leadership sets the book into motion for the learner. The simulations at the end of Parts II and III present specific ways to learn the chapter contents. These simulations are designed to provide experience in applying theory in a 
low-risk setting. It is known that as anxiety increases, perception decreases. When perception decreases, people most often do not think; they merely function intuitively. These intuitive behaviours are derived from practices and experiences earlier in life-from behaviours previously learned. It is also known that in a real management environment, a person's anxiety is generally greater than it is in a classroom or laboratory. This is due to tensions increasing when others are really looking to a person for guidance or are expecting something from that person. Because it takes time for learners to incorporate theory into practice, to think while doing instead of doing and then thinking, the use of simulations provides added experience so that the likelihood of a manager effectively applying theory while in any state of anxiety increases. This experiential model, the group dynamics laboratory, has been widely used in management training and this author has adapted it to health care simulations.

The exercises in Part I of this book are ice-breaking, getting-acquainted activities. They are designed to help in the formation of effective groups and are most appropriately used at the beginning of study in a management and leadership course or programme.

The ultimate goal of this book is identical to the ultimate goal of health care: to assist the client to reach full health potential. In achieving this goal, an intermediate goal of assisting the manager to achieve optimal effectiveness is emphasized. The educational process attends to the unique individual learner. A satisfied manager has a high probability of having staff members who are also satisfied; satisfied staff members have a high probability of having satisfied clients; a satisfied client has a high probability of reaching full health potential. 


\section{Preface to the Macmillan Edition}

I am pleased to introduce the Macmillan edition of Management in Health Care to a British audience. Previously the book was printed and published in the US under the title Management in Nursing by Dr Elaine Lynne La Monica. The new edition, entitled Management in Health Care, has an additional section, Part IV, with six new chapters specially written for it.

The change in title reflects a more general orientation to health care management and was intended to increase the book's appeal to a wider audience of health care professionals and other generalists, in addition to nurses. This was done since it was felt that the recent changes in the National Health Service (NHS) affect everyone working in health care and require them to display more managerial and leadership abilities than ever before.

The present edition of this book is, therefore, intended for health care professionals who have managerial responsibilities in health care or allied health care at supervisory level or above, e.g. staff nurses, ward sister or heads of departments of radiography, physiotherapy, chiropody, medical records, theatre, etc. Included in this group are both purchasers and providers of health care, including staff in directly Managed Units, NHS Trusts, Independent Hospitals, Local Authorities and Voluntary Agencies.

The book is especially intended for those who may be undertaking a management course in higher education at a university or polytechnic. However, it is possible to use the book for private study also.

Although the general focus and structure remain the same, spelling and nomenclature have been altered to reflect British usage. For example, where "nurses" or "nurse managers" have been used in the original "health care manager" or "manager" have been substituted where appropriate.

Some minor additions have also been made to certain chapters. For example, in Chapter 1 Mintzberg's research on managerial roles has been added. 


\section{Introduction to the Macmillan Edition}

Health care in the 1990s is still in a period of transition, following the major government NHS management reforms of the 1980s. These reforms together with the recommendations of the National Health Service Management have considerable implications for the organization of health care throughout the UK. In addition, the NHS and Community Care Bill, which makes provision for the establishment of NHS Trusts, introduces new arrangements for provision of local health services, including contracts between NHS bodies, and new frameworks for the provision of community care. All of this means that now, more than ever, there is a greater need for effective leaders and managers with vision in the health service to implement and effectively manage these changes. To do this, health care professionals require a sound understanding of leadership and management principles together with a sound understanding of the system in which they operate.

This is why I am pleased to join with Dr La Monica in bringing this book to the attention of a British audience. Anyone who diligently studies the theories and principles contained within these pages and who is willing to make the effort to translate the principles into their own practice will be well rewarded with an overall improvement in their managerial performance.

The present volume has been expanded to include a new section, "Management Processes" (Part IV), while in Part III, "Management Responsibilities", two additional chapters have been added: Chapter 19, which covers research related to stress and its management, together with suggested strategies managers might adopt in coping with the negative effects of stress in themselves and others, and Chapter 20, which covers total quality management issues in the delivery of quality health care.

In Part IV, "Management Processes", Chapter 21 covers the historical development of the NHS since its inception and provides an overview of how it has evolved managerially and structurally to the present day, while Chapters 22 and 23 complement the previous chapters by providing a review of the various organizational theories as well as the "nuts and 
bolts" involved in structuring an organization. Chapter 24 discusses organizational culture-a topic which is assuming increasing importance in management literature-and relates it to the NHS. Additional experiential exercises have also been added to complement some of the added chapters.

Philip Ian Morgan 


\section{Contents}

Acknowledgments

$v i$

Preface

Introduction

Preface to the Macmillan Edition

vii

Introduction to the Macmillan Edition

$i x$

$x i i$

xiii

\section{PART I A CONCEPTUAL FRAMEWORK}

1 The Management Process and the Problem-Solving Method

Management and Leadership

The Management Process

Managerial Skills

Role Theory

The Problem-Solving Method

Summary

2 Management and Leadership Theory 16

Classical and Nonclassical Organization Theory 17

General System Theory $\quad 18$

Group Dynamics Laboratory $\quad 22$

Motivation $\quad 25$

Summary $\quad 29$

Experiential Exercises: Ice-Breaking and Getting Acquainted 31

\section{PART II MANAGER RESPONSIBILITIES}

3 Diagnosing Self 53

Conceptual Framework $\quad 53$

Point of View 55

Leader Behaviour Style $\quad 57$

Summary $\quad 58$ 
4 Diagnosing the System $\quad 60$

Maslow's Hierarchy of Needs 62

Hersey and Blanchard's Levels of Readiness 65

McGregor's Theory X and Theory Y 66

Argyris's Immaturity-Maturity Continuum 67

Herzberg's Motivation-Hygiene Theory 69

$\begin{array}{ll}\text { Summary } & 71\end{array}$

5 Leader Behaviour $\quad 75$

Definition of Leadership $\quad 76$

Common Leader Behaviour Styles $\quad 76$

Components of Leader Behaviour 77

Leadership Models $\quad 78$

Determining Appropriate Leader Behaviour Style $\quad 82$

Discussion of Applied Leader Behaviour Theories $\quad 89$

Leader Effectiveness $\quad 90$

Organizational Effectiveness $\quad 91$

Summary $\quad 92$

6 Diagnosing the Task 96

The Vroom and Yetton Managerial Decision-Making Model 97

Application of the Decision Model 98

Discussion of the Model 103

Summary 105

7 Applying the Management Process and the Problem-Solving Method

Problem Identification 108

Problem Definition $\quad 109$

$\begin{array}{lr}\text { Problem Analysis } & 109\end{array}$

Alternative Actions 113

Recommended Action 114

Implementation and Evaluation $\quad 115$

The Management Process 116

$\begin{array}{ll}\text { Summary } & 116\end{array}$

8 Managerial Ethics . . . by Elizabeth M. Maloney, EdD 118

Background to Ethical Concerns 119

Ethics and Morality Defined $\quad 121$

Principles of Ethics-Guidelines 122

Management and the Development of a Moral Climate $\quad 125$

Managerial Options 129

What of the Future?

Summary 
Experiential Exercises: Manager Responsibilities

\section{PART III MANAGEMENT SKILLS}

9 Communication

Definition of Communication $\quad 173$

The Communication Process 174

Purposes of Communication $\quad 175$

Types of Communication $\quad 176$

How Managers Communicate 179

Summary 184

10 Change 186

Force Field Analysis 187

Levels of Change 190

The Change Process 193

Strategies of Change 194

Resistance to Change 196

Combating Resistance to Change 196

Summary 197

11 Power 199

Power Defined 199

Types of Power 200

Sources of Power 201

Uses of Power 202

Summary 204

12 Teaching 206

Identifying Learning Needs 207

Stating the Teaching Priorities 208

Developing Programme Objectives 211

Exploring Teaching Strategies $\quad 212$

Recommending a Programme 216

Summary 216

13 Interviewing 218

What is an Interview? 219

Purposes of an Interview 219

Types of Interview 221

Contingencies of the Interview 222

Principles of Interviewing $\quad 223$

Summary 226 
14 Assertiveness . . . by Patricia M. Raskin, PhD 228

What Is Assertiveness? 229

Why Is Assertive Behaviour Desirable?

Assertive Behaviour in Nurses $\quad 231$

Goals of Assertiveness Training 232

Components of Assertiveness 232

Appropriate Uses of Assertiveness Techniques 236

Monitoring One's Own Assertiveness 238

Assessing and Applying Assertiveness Techniques 238

A Final Note $\quad 239$

Summary $\quad 239$

15 Group Dynamics 242

Purposes for Studying Group Dynamics 243

What to Observe in Groups 243

Group Roles 249

Processing Group Behaviour 252

Common Health Care Groups 253

Summary 261

16 Conflict Resolution 264

Definitions of Conflict 265

Types of Conflict 265

Causes of Conflict 265

The Conflict Process 268

Resolving Conflict $\quad 270$

Outcomes of Conflict 275

Summary $\quad 277$

17 Time Management 280

Philosophy of Time 281

The Time Management Process 283

Time Management Techniques $\quad 285$

Summary 292

18 Performance Appraisal 295

Purposes of the Performance Appraisal 296

Principles of Performance Appraisal 297

Tactics of Performance Appraisal 298

Performance Appraisal Methods 301

A Personal Note on Appraisals 303

Summary 304 
19 Job Stress . . by Philip I. Morgan, PhD 306

Symptoms of Stress $\quad 306$

Definition of Stress 307

Causes of Stress $\quad 309$

Stress and Life Events 311

Stress and Personality 311

A Model of Stress 313

Stress Management $\quad 315$

Stress: A Final Word $\quad 319$

Summary 320

20 Total Quality Management . . by Philip I. Morgan, PhD 323

Development of Total Quality Management 324

Quality Defined 326

Total Quality Management Defined 328

Elements of Total Quality Management 328

The Quality Chain 332

Stages of Quality Management 334

Implementing Total Quality Management 335

Summary 336

Experiential Exercises: Management Skills 339

\section{PART IV MANAGEMENT STRUCTURE AND PROCESSES}

21 Development of the National Health Service ...

by Philip I. Morgan, PhD

445

The National Health Service 1948-1972

445

"Consensus" and "Diplomatic" Management 1972-1982 449

The Griffiths Report 1983-“"General Management" 453

Consumerism-1989 and Beyond 457

Summary $\quad 459$

22 The Environment . . by Philip I. Morgan, PhD 461

The External Environment $\quad 462$

The Internal Environment $\quad 465$

Summary $\quad 467$

23 Formal Organization Design . . . by Philip I. Morgan, PhD 468

Classical Organization Design $\quad 469$

Contingency Theory $\quad 470$ 
Structural Tools $\quad 473$

Future Organizational Structures: "Networks" 483

Summary 485

24 Organizational Culture ... by Philip I. Morgan, PhD 488

Definition of "Culture" 489

Functions of Organizational Culture 491

Factors Influencing the Development of Cultures 492

Cultural Types 494

Changing the NHS Culture-From Role to Task 496

Occupational Cultures 496

Changing the Organizational Culture 497

Implementing a Culture Change Programme 499

Future Organizational Cultures $\quad 501$

Summary $\quad 502$

$\begin{array}{ll}\text { Epilogue } & 504\end{array}$

Appendix: Selected Bibliography on Experiential Learning 505

Author Index $\quad 509$

$\begin{array}{ll}\text { Subject Index } & 517\end{array}$ 